\title{
The Glucose Challenge Test for Screening of Gestational Diabetes
}

\section{Shrestha A, Chawla CD}

Department of Obstetrics and Gynecology

Dhulikhel Hospital - Kathmandu University Hospital

Kavre, Nepal.

\section{Corresponding Author}

Abha Shrestha

Department of Obstetrics and gynecology

Dhulikhel Hospital, Kathmandu University Hospital Kavre, Nepal.

Email: phuche_001@yahoo.com

\section{Citation}

Shrestha A, Chawla CD. The glucose challenge test for screening of gestational diabetes. Kathmandu Univ Med J 2011;34(2)22-6.

\begin{abstract}
Background

The frequency of gestational diabetes mellitus (GDM) is $0.6 \%-15 \%$ of pregnant woman. The modern trend towards the delay starting family is the main factor responsible for increase prevalence of GDM. This condition is associated with the adverse effect on mother and fetus, so it is important to find out the GDM by screening of all the pregnant women.
\end{abstract}

\section{Objective}

To observe the feasibility of using the $50 \mathrm{~g} \mathrm{GCT}$ for all pregnant women attending Dhulikhel Hospital, Obstetric OPD. To determine the incidence of gestational diabetes in the population and to observe the maternal and fetal outcome among those having an elevated GCT level and gestational diabetes.

\section{Methods}

A prospective and analytical study of 1598 pregnant women booked and delivered between June 2009and August 2010. Glucose challenge test (GCT) performed by using 50gm glucose and diagnosis of gestational diabetes performed by using the Carpenter Coustan Criteria. Pregnancy outcomes were assessed by the gestation and mode of delivery. Similarly, neonatal outcomes assessed in terms of birth weights, APGAR scores, congenital abnormalities, hyperbilirubinaemia, hypoglycaemia or respiratory distress syndrome.

\section{Results}

The detected incidence of gestational diabetes was $0.75 \%$. With the threshold plasma glucose level at $140 \mathrm{mg} / \mathrm{dl}, 198$ women needed to undergo the $100 \mathrm{~g}$ oral glucose tolerance test and 12 women had gestational diabetes. The diagnostic yield was $6.06 \%$. Perinatal outcome was similar to the rest of the women with normal glucose challenge test.

\section{Conclusions}

The 50g GCT is feasible and also helps to find out GDM. It is easy, user friendly, cheap and convenient for screening purpose.

\section{KEY WORDS}

Glucose challenge test, gestational diabetes, oral glucose tolerance test.

\section{INTRODUCTION}

Gestational diabetes (GDM) is defined as glucose intolerance of variable severity with onset or first recognition during the present pregnancy and reverting to normal after the puerperium. ${ }^{1}$ The frequency of gestational diabetes mellitus is $0.6 \%-15 \%$ of pregnant woman. ${ }^{2}$ Whereas the study performed in Singapore showed the incidence ranges from $1.1 \%$ to $13.3 \%$ of the population. As the modern trend is towards the delay starting family which is the main factor responsible for increase prevalence of GDM. Since, this condition is associated with the adverse effect on mother and fetus, so it is important to find out the GDM by screening of all the pregnant women. ${ }^{3}$ The adverse effect associated with GDM is ketoacidosis, vasculopathy, infection of genital tract, pre-eclampsia, intrauterine growth retardation, macrosomia, polyhydramnios and sudden intra-uterine death. It has been reported that $50 \%$ of these patients will become diabetic in the 15 years following pregnancy. ${ }^{4}$ The adverse effects in newborns are birth trauma because of macrosomia, neonatal hypoglycaemia, respiratory distress syndrome and congenital abnormalities. The oral glucose tolerance test (OGTT) is considered as the gold standard for diagnosis of diabetes mellitus. The pregnant women with positive history and risk factors are screened for GDM and also sent for OGTT. The results following this screening is that $40 \%$ of GDM are left unidentified as there is relatively low sensitivity and specificity of the screening 
criteria..$^{5-7}$ Most obstetricians are still reluctant to perform screening among the pregnant women with no risk factors because they are not convincing of the results. The main aim of our study is to observe the feasibility of using the $50 \mathrm{Ggct}$ (glucose challenge test) for all the pregnant women attending $\mathrm{DH}$ ( Dhulikhel hospital) obstetric OPD, to determine the incidence of GDM in pregnant women and to observe the maternal and fetal outcome among those having an elevated GCT level and gestational diabetes.

\section{METHODS}

It was a prospective, analytical study carried out in all the pregnant women attending Dhulikhel hospital obstetrics out patient department between June 2009 to August 2010 after the IRC approval. There were total 1598 pregnant women who were booked as our antenatal cases having no previous history of diabetes mellitus.

These patients underwent the 50g GCT between 24 and 28 weeks of gestation or at booking( if they come after 28 weeks of gestation.) A $50 \mathrm{~g}$ glucose drink was administered after the antenatal consultation and 60 minutes later venous blood was drawn for plasma glucose estimation. The glucose oxidase method was performed to estimate the plasma glucose level. A plasma glucose level of $140 \mathrm{mg} / \mathrm{dl}$ or higher was considered a positive test and these women were considered for 100g OGTT. Using the Carpenter Coustan criteria, a diagnosis of GDM was made if the plasma glucose level: fasting, $95 \mathrm{mg} / \mathrm{dl}$, in 1 hour $=180 \mathrm{mg} / \mathrm{dl}$; in $2 \mathrm{~h}=155 \mathrm{mg} / \mathrm{dl}$; and in 3hour= $140 \mathrm{mg} /$ dl. (Proceedings of the fourth International WorkshopConference on Gestational Diabetes Mellitus). All patients who had GDM were referred to a dietician and jointly managed by an internist and an obstetrician. They were put on a 1800 kilocalorie diet and started on insulin when indicated. For those women whose sugar levels were well controlled on diet, pregnancy was allowed to progress for spontaneous labour, while for those women who required insulin therapy, pregnancy was terminated at 39 weeks of gestation. After delivery, all infants of diabetic mothers were assessed for congenital malformations, hypoglycaemia and other electrolyte and respiratory disorders. The outcome of the pregnancies was assessed by the gestation and mode of delivery and neonatal outcomes in terms of birth weights, apgar scores, congenital abnormalities, hyperbilirubinaemia, hypoglycaemia or respiratory distress syndrome. The results were analyzed by Microsoft Excel 2010 software using simple manual analysis of frequency and percentage.

\section{RESULTS}

A total of 1598 pregnant women were screened antenatally with the 50g GCT. Of these, 198(12.3\%) women were found to have a $50 \mathrm{~g} \mathrm{GCT}$ value of greater or equal to $140 \mathrm{mg} / \mathrm{dl}$. They underwent formal OGTT and $12(0.75 \%)$ women were found to have GDM.
Table 1. The results of the $50 \mathrm{~g}$ GCT and abnormal OGTT among different

casts.

\begin{tabular}{lll}
\hline Caste $(n=1598)$ & GCT $\geq 140 m g / d l ~(n=198)$ & Abnormal OGTT $(n=12)$ \\
\hline Brahmin $(n=215)$ & $30(15.2 \%)$ & - \\
\hline Chettries $(n=375)$ & $37(18.7 \%)$ & - \\
\hline Newars $(n=412)$ & $49(24.7 \%)$ & $2(16.7 \%)$ \\
\hline Tamangs $(n=508)$ & $66(33.3 \%)$ & $8(66.6 \%)$ \\
Others $(n=88)$ & $16(8.1 \%)$ & $2(16.7 \%)$
\end{tabular}

$50 \mathrm{~g} \mathrm{GCT} \geq 140 \mathrm{mg} / \mathrm{dl}$ was seen in 66 cases(33.3\%) of Tamangs and abnormal OGTT in eight(66.6\%) as shown in table 1.

Table 2. The results of the $50 \mathrm{~g}$ GCT and abnormal OGTT in different age groups.

\begin{tabular}{lll} 
Age $(n=1598)$ & GCT $\geq 140 \mathrm{mg} / \mathrm{dl}(\mathrm{n}=198)$ & Abnormal OGTT $(n=12)$ \\
\hline $15-19(n=475)$ & $31(15.7 \%)$ & - \\
\hline $20-25(n=684)$ & $87(43.9 \%)$ & $7(58.3 \%)$ \\
\hline $26-30(n=257)$ & $72(36.4 \%)$ & $2(16.7 \%)$ \\
$31-35(n=149)$ & $5(2.5 \%)$ & $1(8.3 \%)$ \\
$36-40(n=33)$ & $3(1.5 \%)$ & $2(16.7 \%)$
\end{tabular}

$50 \mathrm{~g} \mathrm{GCT} \geq 140 \mathrm{mg} / \mathrm{dl}$ in age groups of $20-25$ years was seen in 87 cases(43.9\%) and abnormal OGTT in seven(58.3\%) as shown in table 2.

Table 3. The results of the $50 \mathrm{~g}$ GCT and abnormal OGTT in Pregnant women with different Body Mass Index.

\begin{tabular}{lll}
\hline BMI $(n=1598)$ & GCT $\geq 140 m g / d I(n=198)$ & Abnormal OGTT(n=12) \\
\hline $18-20(n=531)$ & $20(10.1 \%)$ & $1(8.3 \%)$ \\
\hline $21-25(n=1027)$ & $52(26.3 \%)$ & $2(16.7 \%)$ \\
$26-30(n=28)$ & $119(60.1 \%)$ & $5(41.6 \%)$ \\
$31-35(n=7)$ & $3(1.5 \%)$ & $2(16.7 \%)$ \\
$>35(n=5)$ & $4(2 \%)$ & $2(16.7 \%)$
\end{tabular}

$50 \mathrm{~g} \mathrm{GCT} \geq 140 \mathrm{mg} / \mathrm{dl}$ was seen in $119(60.1 \%)$ and abnormal OGTT in five(41.6\%) pregnant women with BMI(basal metabolic index) 26-30 as shown in table 3.

Table 4. The results of 50g GCT and abnormal OGTT in pregnant women with different risk factors and without risk factors.

\begin{tabular}{|l|l|l|l|}
\hline Risk factors & $\begin{array}{l}\text { Number } \\
(\mathrm{n}=1598) \\
\text { Family history of } \\
\text { diabetes }\end{array}$ & $\begin{array}{l}\mathrm{GCT} \geq 140 \mathrm{mg} / \\
\mathrm{dl}(\mathrm{n}=198) \\
4(2 \%)\end{array}$ & $\begin{array}{l}\text { Abnormal } \\
\text { OGTT(n=12) }\end{array}$ \\
\hline $\begin{array}{l}\text { Obesity } \\
\begin{array}{l}\text { Multiparous(>3 deliver- } \\
\text { ies) }\end{array}\end{array}$ & $\begin{array}{l}40(2.5 \%) \\
21(1.3 \%)\end{array}$ & $\begin{array}{l}19(9.6 \%) \\
12(6.1 \%)\end{array}$ & - \\
\hline $\begin{array}{l}\text { Previous big baby } \\
\begin{array}{l}\text { Previous unexplained } \\
\text { Intrauterine Death(IUD) }\end{array}\end{array}$ & $3(0.2 \%)$ & $1(0.5 \%)$ & $1(8.3 \%)$ \\
\hline $\begin{array}{l}\text { Previous baby with } \\
\text { congenital anomaly }\end{array}$ & $1(0.1 \%)$ & $2(1 \%)$ & $1(8.3 \%)$ \\
No risk factor & $1510(94.5 \%)$ & $160(80.8 \%)$ & $8(66.7 \%)$ \\
\hline
\end{tabular}

$50 \mathrm{~g}$ GCT $\geq 140 \mathrm{mg} / \mathrm{dl}$ and abnormal OGTT in pregnant women with different risk factors and without risk factors are as shown in table 4. 
Out of 1510 pregnant women without risk factors 160 (10.5\%) had raised GCT and out of 160 raised GCT 8(5\%) had abnormal OGTT and 152 (95\%) had normal OGTT. Likewise, out of 88 pregnant women with risk factors 38 (43.1\%) had raised GCT and out of 38 raised GCT, four(10.5\%) had abnormal OGTT and 34(89.5\%) had normal OGTT.

The maternal outcome with GCT $\geq 140 \mathrm{mg} / \mathrm{dl}$ showed that there was no morbidity in $186(75.5 \%)$ women whereas pre-eclampsia in seven(13.6\%) and abruption placentae was in five(9.9\%) out of 198 women.Similarly, the maternal outcome with abnormal OGTT showed that there was no morbidity in seven(58.3\%), pre-eclampsia in three(25\%) and abruption placenta in two(16.6\%) out of 12 women.

Table 5. Showing perinatal outcome amongst women with GCT $\geq 140 \mathrm{mg} / \mathrm{dl}$.

\begin{tabular}{ll} 
Perinatal outcome & GCT $\geq 140 \mathrm{mg} / \mathrm{dl}(\mathrm{n}=198)$ \\
$\begin{array}{l}\text { Gestational age at birth } \\
\text { (weeks) }\end{array}$ & $38.2 \pm 1.3$ \\
\hline Birth Weight(g) & $3710 \pm 218.2$ \\
\hline Length $(\mathrm{cm})$ & $48 \pm 2.2$ \\
\hline Macrosomia & $8(4.04 \%)$ \\
\hline Premature birth & $29(14.6 \%)$ \\
\hline
\end{tabular}

The different perinatal outcomes among the pregnant women with GCT $\geq 140 \mathrm{mg} / \mathrm{dl}$ are shown in table 5 .

Table 6. Different perinatal outcome with abnormal OGTT.

\begin{tabular}{ll} 
Fetal outcome & Abnormal OGTT( $n=12)$ \\
\hline Macrosomia & $6(50 \%)$ \\
\hline Premature birth & $4(33.33 \%)$ \\
\hline Neonatal jaundice & $1(8.3 \%)$ \\
Congenital heart disease & $1(8.3 \%)$
\end{tabular}

The perinatal outcome with abnormal OGTT showed that there was macrosomia in six(50\%) and premature birth in four(33.3\%) out of 12 pregnant women. as shown in table 6.

\section{DISCUSSION}

The glucose challenge test (GCT) performed in all the pregnant women helps to screen out the women with GDM. ${ }^{5}$ Since, the GDM is notorious for causing adverse effects in pregnancy and also fetal outcome, so there is clear benefit by screening of GDM as it helps in early treatment. ${ }^{3}$

Since the $50 \mathrm{~g}$ Glucose can easily be available for the GCT purpose and also can be performed in Out patient basis, so it is easy, work friendly, cheap and convenient for screening purpose similar to study performed by Wong $L$ and Tang ASA. ${ }^{8}$ Apart from that, the pregnant women not required to come with fasting and also they appreciate the test after explaining the importance. Till now no women complained about the adverse effects of test. So, it is feasible to perform 50g GCT in all pregnant women.

Of the women who underwent the $50 \mathrm{~g} \mathrm{GCT}, 198(12.39 \%)$ women were found to have an elevated level greater or equal to $140 \mathrm{mg} / \mathrm{dl}$ and $12(0.75 \%)$ women were found to have GDM. So, the incidence of GDM was $0.75 \%$ in pregnant women attending Dhulikhel Hospital. and the diagnostic yield was $6.06 \%$. The incidence in our study is lower than that of the study performed by Wong $L$ and Tang ASA which reported the incidence of $8.2 \%$ and diagnostic yield of $22.6 \%{ }^{8}$ This could be because they use the cut off point of $7.1 \mathrm{mmol} / \mathrm{I}$. Like wise study performed by the Yang HX et al showed the incidence of GDM $2.7 \%$ which was somehow comparable to our results. ${ }^{9}$ Similarly study performed by King $\mathrm{H}$ and Ray $\mathrm{R}$ et al showed the incidence comparable to our results. 2,10

The study performed by Wong $L$ and Tang ASA ${ }^{8}$ showed that every one in five elevated GCT found to have GDM which was similar to our results as in our case every one in six elevated GCT found to have GDM. In 1973, O'Sullivan et al proposed that a single sample of glucose tolerance performed without dietary preparation could provide an acceptable screening compromise. ${ }^{12}$ Hence, developed the concept about the 50g GCT. So study performed in 19,798 women, O'Sullivan reported a sensitivity of $79 \%$ and specificity of $87 \%$ using a threshold value of $130 \mathrm{mg} /$ dl whole blood (or $7.9 \mathrm{mmol} / \mathrm{l}$ plasma). Based on his study, OGTT done for positive history or obstetrical risk factors yielded poor results with a sensitivity rate of $63 \%$ and specificity rate of $56 \%$.In the 1980 s those cut-off points were adapted to modern methods for measuring glucose and applied to the modern definition of gestational diabetes glucose intolerance with onset or first recognition during pregnancy. ${ }^{12}$

Cousins, favored a cut-off of $130 \mathrm{mg} / \mathrm{dl}(7.2 \mathrm{mmol} / \mathrm{l})$ while Carpenter, suggested the threshold value be set at $135 \mathrm{mg} /$ dl $(7.5 \mathrm{mmol} / \mathrm{l}) .{ }^{7,13}$ When the threshold was set at $140 \mathrm{mg} /$ $\mathrm{dl}$, we discovered that $12.39 \%$ of the population would need to be further tested with the OGTT and the diagnostic yield was $6.06 \%$. Since we do have poor patients came to our Out patient service so, for economic reasons, we recommend the threshold of $140 \mathrm{mg} / \mathrm{dl}$. At this threshold value, only one out of six of the screened population needs to undergo the OGTT.

We observed the epidemiological data to see any epidemiological risk factors associated with a raised GCT or OGTT result. Study performed by Ray $\mathrm{R}$ et al showed that older age that is 30 years and above, Chinese ethnic group, maternal obesity (body mass index $>$ or $=25$ ) and history of $>$ or $=4$ pregnancies were associated with raised GCT levels. ${ }^{10}$ Our results also showed that 66 (33.3\%) Tamang women and $49(24.7 \%)$ newars that is mongol groups had high GCT. Out of 12 abnormal OGTT, eight(66.6\%) Tamang women and two(16.7\%) Newar women had abnormal OGTT. Also the patient with $\mathrm{BMI}>26$ had raised GCT and abnormal OGTT which is similar to study performed by Ray $R$ et al but 
differ in presentation of age group as in our case the raised GCT and abnormal OGTT was in age group $>20$ years. ${ }^{10}$ It may be because in our study population women become pregnant in their younger age. Similarly study performed by Wong $L$ and Tand ASA showed no statistical significant between the raised GCT with respect to age, race and body mass index, like that of study performed by Bhat RA et al. ${ }^{8,14}$

One hndred and sixty(10.5\%) out of 1510 pregnant women without risk factors had raised GCT, and out of 160, eight(5\%) had abnormal OGTT. Among pregnant lady with risk factor, $38(43.1 \%)$ out of 88 had raised GCT and four(10.5\%) out of 38 had abnormal OGTT, which is comparable to study performed by Griffin et al. ${ }^{15}$

Regarding the maternal outcome in ladies with elevated GCT and abnormal OGTT, the pre-eclamsia was seen in $13.6 \%$ and $25 \%$ whereas the abruption placenta was seen in $9.9 \%$ and $16.6 \%$ respectively. Our study is comparable to the study performed by Kim et al, Lindsay et al.and Yogev et al. ${ }^{16-18}$

\section{REFERENCES}

1. Freinkel N, Gabbe SG, Hadden R. Summary and recommendations of the Second International WorkshopConference on Gestational Diabetes Mellitus. Diabetes 1985; 34:123-6.

2. King $\mathrm{H}$. Epidemiology of glucose intolerance and gestational diabetes in women of childbearing age. Diabetes Care 1998;21(Suppl.2):B9-B13(s).

3. Wang KW, Balakrishnan V, Liaw PCY, Chua EKM, Vengadasalam D, Tan YT. Gestational diabetes: What size the problem? Singapore Med J 1988; 29:53-5.

4. O'Sullivan J B. Body weight and subsequent diabetes mellitus. JAMA 1982; 248:949-52.

5. Carpenter MW, Coustan DR. Criteria for screening tests for gestational diabetes. Am J Obstet Gynecol 1982; 144:768-73.

6. Coustan DR, Nelson C, Carpenter MW, Carr SR, Rotondo L, Widness JA. Maternal age and screening for gestational diabetes: a population based study. Obstet Gynecol 1989; 73:557-61.

7. Moses R, Griffiths R, Davis W. Gestational diabetes: do all women need to be tested? Aust NZ Obstet Gynaecol 1995; 35:387-9.

8. Wong $L$ and Tan ASA. The Glucose Challenge Test For Screening Gestational Diabetes in Pregnant Women with No risk Factors. Singapore Med J .2001;42(11):517-521.

9. Yang HX, Gao XL, Dong Y, Shi CY. Analysis of oral glucose tolerance test in pregnant women with abnormal glucose metabolism. CMJ. 2005;118(12);995-99.
Similarly in perinatal outcome, pregnant women with elevated GCT and abnormal OGTT showed macrosomia in $4.04 \%$ and $50 \%$, premature birth in $14.6 \%$ and $33.3 \%$ respectively. Neonatal jaundice and congenital heart disease in $8.3 \%$ was seen only in abnormal OGTT. Our results also similar to the study performed by different authors. . $^{17,19,20,21}$

\section{CONCLUSIONS}

The 50g GCT when performed on all pregnant women is feasible and also helps to find out GDM. It is easy, work friendly, cheap and convenient for screening purpose It was well tolerated by all the patients. We recommend that the threshold value be set at $140 \mathrm{mg} / \mathrm{dl}$ because only one-fifth of the population would need to undergo the OGTT and the diagnostic yield was $6.06 \%$. Because of preventable adverse outcome of both maternal and fetus, it is worthwhile to perform early detection of GDM by screening.

10. Ray R, Heng BH, Lim C, Ling SL. Gestational diabetes in Singaporean women: use of the glucose challenge test as a screening test and identification of high risk factors. Ann Acad Med Singapore 1995; 25:504-8.

11. O'Sullivan JB, Mahan CM, Charles D, Dandrow RV. Screening criteria for high risk gestational diabetic patients. Am J Obstet Gynecol 1973; 116:895-900.

12. American Diabetes Association. Report of the expert committee on the diagnosis and classification of diabetes mellitus. Diabetes Care 2003;26(Suppl. 1):S5-S20.

13. Cousins L, Baxi L, Chez $R$, et al. Screening recommendations for gestational diabetes mellitus. Am J Obstet Gynecol 1991; 165:493-6.

14. Bhat RA, Venkatesh D, Kumar PN. Influences of one elevated glucose tolerance test value on pregnancy outcome. The internet journal of gynecology and obstetrics.2006;6(1).

15. Griffin ME, Coffey $M$, Johnson $H$, Scanlon P, Foley $M$, Stronge J et al. Universal vs. risk factor-based screening for gestational diabetes mellitus: detection rates, gestation at diagnosis and outcome. Diabetic Medicine 2000;17:26-32.

16. Kim HS, Chang KH, Yang JJ, Yang HC, Lee HJ, Ryer HS. Clinical outcomes of pregnancy with one elevated glucose tolerance test value. Int J Gynecol Obstet 2002;78:131138(s).

17. Lindsay MK, Graves W, Klein L. The relationship of one abnormal glucose tolerance test value and pregnancy complications. Obstet Gynecol 1989;73:103-106(s). 